\title{
WELL-BEING FRAMEWORK AS A CONTRIBUTOR TO SUSTAINABILITY
}

\author{
NILUFER SAGLAR ONAY ${ }^{1} \&$ VALERIA MINUCCIANI $^{2}$ \\ ${ }^{1}$ Istanbul Technical University, Faculty of Architecture, Turkey \\ ${ }^{2}$ Politecnico di Torino, Department of Design and Architecture, Italy
}

\begin{abstract}
This work aims to propose an environmental design framework in order to contribute to sustainability with well-being criteria focusing on human factors. Thus, the ways that buildings and interior spaces affect our well-being and quality of life have to be considered in the general framework of sustainable design. Space can be regarded as the most important concrete aspect that can be controlled by the designer and can directly affect human well-being. Regarding the environment as a whole, this approach focuses on interiors as the basic spatial elements where human perform a great amount of their basic activities. Designers need to handle the issue of well-being with a methodological approach as it is very difficult to achieve with an intuitive attitude. There are several requirements that need to be fulfilled in order to create the environment that can promote user's well-being. The framework proposal, consisting of contextual, functional, psychological, social, ergonomic and sensory requirements as basic design criteria, aims to support both theoretical and practical activities regarding well-being in all living environments as a crucial component of sustainability. In this sense at the last phase of the study, the framework is used to evaluate examples of traditional houses in Turkey and Italy in order to reveal their characteristics that contribute to well-being. After discussing the efficiency of design criteria for wellbeing and applying it to traditional home environments, further research needs to focus on contemporary design practices. These may include evaluation of common design approaches as well as built environment.
\end{abstract}

Keywords: well-being, interior space, design criteria, sustainability.

\section{INTRODUCTION AND LITERATURE REVIEW}

According to Naci and Ioannidis [1] wellness refers to diverse and interconnected dimensions of physical, mental, and social well-being that extend beyond the traditional definition of health. It includes choices and activities aimed at achieving physical vitality, mental alacrity, social satisfaction, a sense of accomplishment, and personal fulfilment. Desmet and Pohlmeyer [2] define well-being as a broad concept that represents an individual's overall quality of life. Quality of life comprises multidimensional factors that include everything from physical health, psychological state, level of independence, family, education, wealth, religious beliefs, a sense of optimism, local services and transport, employment, social relationships, housing and the environment [3].

Lyubomirsky et al. [4] discuss that three major factors contribute to people's levels of well-being: 1) their happiness set point (i.e., the genetically determined stable level of happiness, which has been shown to account for approximately $50 \%$ of the variance in individual differences in well-being), 2) their life circumstances (e.g., factors such as income, marital status, or religiosity, which are typically found to account for roughly $10 \%$ of individual differences in well-being), and 3) positive cognitive, behavioural, and goal-based activities (which have the potential to account for a significant portion - up to $40 \%$ - of individual differences in well-being). While we consider these three components, we see that the third one can highly be effective by the environment that we live in.

Well-being cannot be considered apart from culture. Although some features can be regarded as universal, some change according to different cultures. Ryff and Singer [5] 
posited that purpose in life, quality relationships, self-regard, and a sense of mastery are universal features of well-being. According to Tov and Diener [6], cultures should differ in SWB (Subjective Well-being) to the extent that they provide people with different levels of autonomy, meaning, and relationships. In this sense the spatial reflections of well-being should also be considered together with cultural aspects. On the other hand, studies on the relation between culture, environment and SWB are very rare.

If we consider studies about well-being and environment, we come across research that focus on biological aspects. Biologist Stephen Boyden [7] in an article on the biological foundations of well-being, distinguishes between "survival needs" and "well-being" needs. Survival needs deal with aspects of the environment that directly affect human health, such as clear air and water, lack of pathogens or toxins, and opportunity for rest and sleep. Wellbeing needs, on the other hand, are more indirect in their locus of impact. These needs affect overall health through their relationship to fulfilment, quality of life, and psychological health. Where failure to satisfy survival needs may lead to serious illness or death, failure to satisfy the well-being needs produces the "grey life" of psychosocial maladjustment and stress related illnesses. Taken as a whole, the research by Boyden and others identifies wellbeing needs that should be addressed in building design:

- Opportunity to engage in spontaneous social encounters.

- Opportunity for relaxation and psychological restoration.

- Opportunity for privacy and for movement between interaction and solitude, as desired.

- Opportunity for learning and information sharing.

- Opportunity for connection to the natural environment.

- Opportunity for regular exercise.

- Sound levels not much above or below that of nature.

- Meaningful change and sensory variability.

- An interesting visual environment with aesthetic integrity.

- Sense of social equity and respect.

- Ability to maintain and control personal comfort.

- Making sense of the environment.

Recently, Petermans and Pohlmeyer [8] discussed the potential of Interior Architecture to contribute to subjective well-being and pointed to the value of applying a human-centered perspective in the design process. They also introduced the Positive Design framework, developed by Desmet and Pohlmeyer [2]. This framework includes three main components of subjective well-being which are defined as pleasure, personal significance and virtue. It can be regarded as a general study that proposes a positive approach to designing for human well-being.

Brey [9] argue that well-being for a particular person cannot be determined objectively, through objective criteria independently from that person. It requires an understanding of that person, which may include knowledge of his or her preferences, desires, values, traits, and social and cultural embeddedness. As well-being is always intended for human, the main point of departure should be understanding human needs and feelings. In this sense wellbeing is always subjective; very difficult, almost impossible to measure. On the other hand designers may explore this subjectivity with a balanced methodology in order to understand the changing range of criteria that build up well-being. 


\section{A METHODOLOGICAL APPROACH FOR WELL-BEING IN INTERIORS}

While considering major factors that contribute to well-being, it is important to differentiate those that can be controlled. Among controllable factors, the natural and built environment must be considered as a very important issue strongly connected to positive cognitive, behavioural, and goal-based activities. Therefore, space can be regarded as the most important concrete aspect that can be controlled by the designer and can directly affect human well-being. Regarding the environment as a whole, this approach focuses on interiors as the basic spatial elements where human perform great part of their basic activities.

As stated above, well-being in interiors is extremely subjective and it is very difficult to measure with objective criteria. On the other hand, designers need to handle the issue of wellbeing with a methodological approach, as it is very difficult to achieve well-being with an intuitive approach. There are several requirements that need to be fulfilled in order to create the environment that can promote user's well-being (Fig. 1). These requirements are different than general requirements of design for well-being as they are strongly connected to space and context. Moreover all these requirements are in relation to each other and they are subject to cultural differences regarding users with different backgrounds.

\subsection{Connection to context}

Just like architecture, the interior has to convey a message about its existence, about its context and content. This is only possible if design components are integrated to each other with a design approach that considers the natural and built environment as a whole without ignoring human scale and senses. In order to understand a building, it is necessary to grasp the exterior forces that shape it. Connection to context is the most important design criteria that creates architectural and spatial identity by differentiating buildings/spaces with context related data. Contextual ties can be discussed in terms of location, orientation, entrance, openings, surrounding buildings /spaces, infrastructure and natural aspects.

A growing body of knowledge supports the role of contact with nature in human wellbeing. Kellert [11] notes that contact with nature has been found to enhance recovery from illness, that people living in proximity to open spaces report fewer health and social

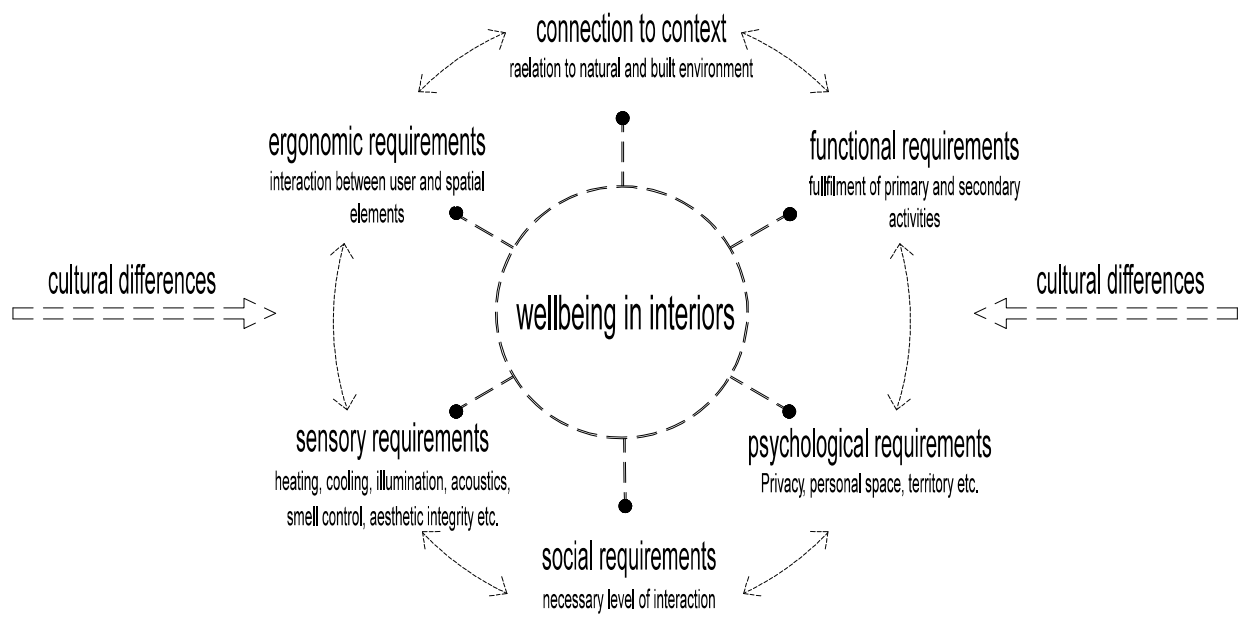

Figure 1: Well-being framework for interiors. 
problems as well as superior quality of life and a stronger sense of place, that office settings with natural environmental features improve worker performance and motivation [11]. These studies provide scientific support for the assumption that contact with nature is critical to human well-being.

\subsection{Functional requirements}

In general terms functional needs can be regarded as the basic needs in living environments intended for a certain purpose and they are shaped by the main activities that take place in and around buildings. For a certain interior, the functional requirements may affect the organization of all interior elements such as furniture, lighting etc. The most efficient way of understanding functional requirements is to understand potential user's intended activities and their way of performing these activities. For multipurpose spaces, functional requirements need to be handled with a flexible approach, which give the possibility to use the same space for different purposes at different times or even for different user profiles. Fig. 2 shows 50 families' functional preferences to use their own home environments in mass housing units in Istanbul. This study aims to understand where, when and how users perform the main activities that take place in home environments in order to create multipurpose and flexible solutions to fulfil functional requirements. The success in determining these requirements has a significant effect on well-being of inhabitants as most family members including women and children pass more than 50 percent of their day at home.

\subsection{Ergonomic requirements}

Ergonomic requirements in interiors are related to the connection between human and space, mainly including physical and cognitive aspects, which help to fulfil a certain task. While physical ergonomics relate to physical activity mainly concerned with human anatomical, anthropometric, psychological and biomechanical characteristics, cognitive ergonomics focuses on mental processes regarding interactions among humans and surroundings [13]. In this sense, user's capabilities and limitations in seeking to ensure the necessary task define ergonomic requirements.

According to Phesant [14], human capacities and limitations, can be understood through a repertoire of investigative methods. Among these two particular techniques deserve special attention: task analysis and user trial. Task analysis state what the user is actually going to do with the product/system/environment. An effective task analysis will clarify the overall
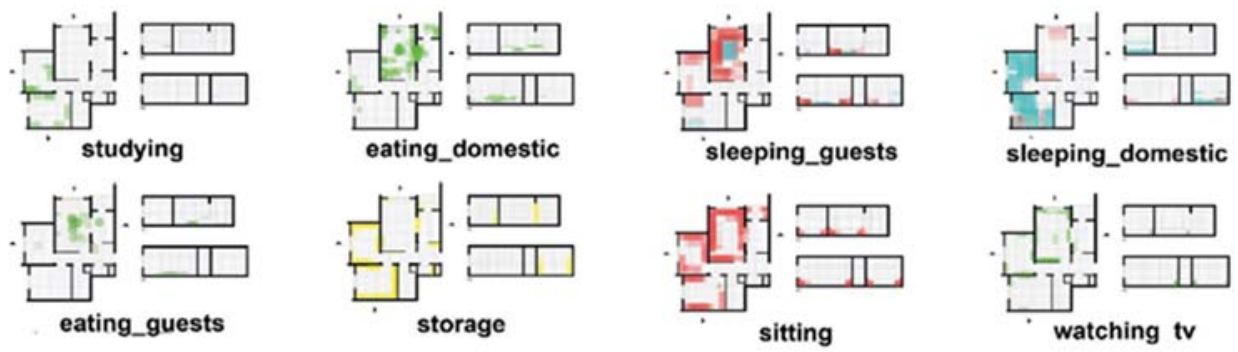

Figure 2: 50 families' functional preferences to use their own home environments in mass housing units in Istanbul [12]. 
goals of the project, establish the criteria that need to be met, point out the most likely areas of mismatch, and so on. On the other hand, user trial is an experimental investigation in which a sample of people tests a prototype version of the product under controlled conditions.

\subsection{Psychological requirements}

Self-determination theorists [15], [16] maintain that well-being hinges on the fulfilment of three basic innate psychological needs which are defined as:

- Competence: Seek to control the outcome and experience mastery;

- Relatedness: Desire to interact, be connected to, and experience caring for others;

- Autonomy: Desire to be causal agents of one's own life and act in harmony with one's integrated self.

According to Kupfer [17] autonomy requires a conception of self for which privacy is indispensable. Privacy is a necessary condition for the development of an autonomous self and it is strongly linked to space. In this sense, environments should be responsive in terms of privacy and control. According to Namazian and Mehdipour [18] environments that emphasize only either very little interaction or a great deal of interaction are too static and will not be responsive to changing privacy needs so environmental designers should try to create environments that permit different degrees of control over contact with others.

\subsection{Social requirements}

As people live in community, well-being of individuals is related to well-being of others and the interaction between individuals and groups. Keyes [19] defines social well-being as an individual's self-report of the quality of his or her relationship with other people, the neighbourhood and the community.

According to Keyes and Shapiro [20] social well-being has 5 dimensions including social integration (the quality of one's relationship to society), social contribution (evaluation of one's value to society), social coherence (perception of the quality, organization and operation of the social world), social actualization (evaluation of the potential and the trajectory of society) and social acceptance (construal of society through the character and qualities of other people as a generalized category). Although they seem unrelated to space, our activities promoting social well-being are directly affected by spatial properties. The spatial aspects of social well-being are related to qualities that enrich social life. In this sense, interiors should provide the chance for social encounters at desired level for everyone. Moreover they should support and encourage social activities creating a balance between public, semi-public and private places. In the research project in Istanbul mentioned above, the well-being of users was mostly related to their relationship with their neighbours. Meeting with their neighbours in order to fulfil their social rituals was more important than many other physical aspects of space. While they were transferred to apartment blocks from scatter housing their most important fear was to lose their social contacts.

\subsection{Sensory requirements}

Sensory requirements are extremely effective on well-being. Ventilation, lighting, heating, cooling and acoustics are issues to be handled with special expertise. Interior designers need to pay attention both on ways to fulfil these requirements and their effects on human senses. 
Pallasma argues that [21] every touching experience of architecture is multi-sensory; qualities of space, matter and scale are measured equally by the eye, ear, nose, skin, tongue, skeleton and muscle. Relatedly Zumthor [22] states that we perceive atmosphere through our emotional sensibility, which is a form of perception that works incredibly quickly. We are capable of immediate appreciation, of a spontaneous emotional response. So atmosphere can be regarded as the essence of space, which we perceive through spatial experience.

According to Unwin [23] in our experience of architecture, basic architectural elements and the places they identify are modified by light, colour, sound, temperature, air movement, smell and the qualities and textures of the materials used. Possible configurations of basic and modifying elements are probably infinite. Therefore, as time goes on, spatial experience and spatial atmosphere changes continuously with the modifying elements of architecture. Sometimes these elements can be much more important than the physical definition of space as they stimulate all our senses [24]. So, we need to take into account the effects of all these modifying elements in order to understand how they change.

\section{A CASE STUDY: EVALUATION OF WELL-BEING DETERMINANTS IN TRADITIONAL HOME ENVIRONMENTS IN TURKEY AND ITALY}

Because of the lack of artificial environment control systems, vernacular architecture examples were mostly very successful in being integrated with the natural environment especially responding in an efficient way to climate and seasonal changes. Humankind accumulated the experience gained through the centuries, made its living culture a part of this environment, and created its settlement to accord with climatic conditions, the sun, wind and nature. He differentiated the specifications of these built environments in parallel with the area's unique features, and in accordance with that society's culture, social and economic data [25].

In this part of the study, traditional home environments from different cultural contexts will be evaluated in terms of their responses to the basic requirements of well-being discussed in the previous part of the paper.

\subsection{The Turkish house}

Although substantial variations in size, configuration and regional characteristics have occurred, certain basic and constant features establish the Turkish house as a distinct type, fixed by convention and tested through centuries. One of these is its timber frame and infill construction, with the infill material ranging from bricks to wood (bagdadi), plastered over in lesser examples and finished in wood in the more elaborate ones. Another feature is the solidity of the ground floor (reserved for hay storage, animals, carriages and services, etc.), above which a much lighter and projecting living floor is raised on stilts. Other characteristic features include rows of modular windows, derived from the logic of the timber frame, and a pitched roof covered with round tiles [26]. The cubic extensions surrounded by windows on the upper floors called "cumba" create strong contextual relation with the neighbouring environment.

The Turkish house responds to climate changes with its overall design and connection to contextual aspects. By employing the substantial knowledge accumulation, both the spatial organization and orientation of rooms and the use of local materials and construction techniques were effective in creating simple but very clever solutions. Küçükerman [27] points out that houses in Turkish settlements were provided with spaces both "open-cool" and "closed-well protected" in accordance with different seasonal requirements. Küçükerman describes and terms these spaces: the "open-cool" summer room is a space that 

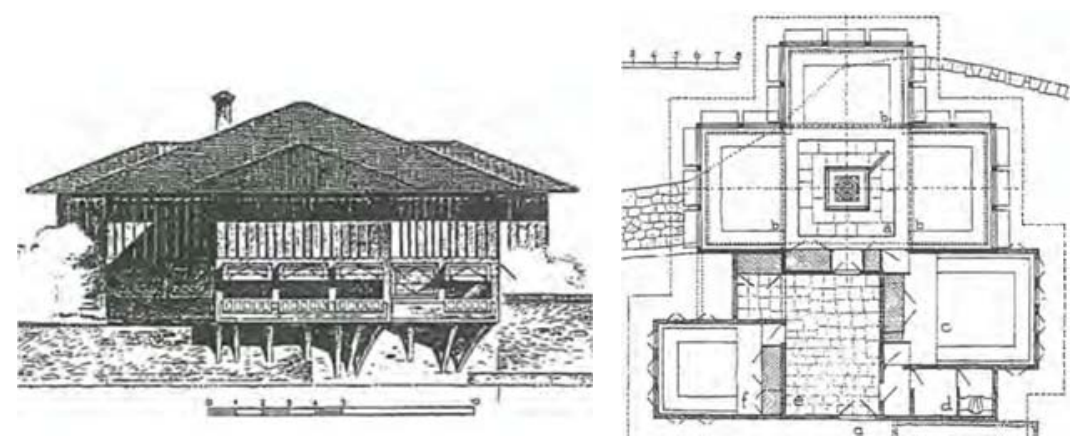

Figure 3: Amcazade Huseyin Pasa Yalisi, Istanbul, I699. One of the oldest surviving examples of the Turkish house.

remains relatively cool by being situated in a direction that is open to air flows, and with thinner walls and floors, and wide and large windows. The "closed-well protected" room, on the other hand, is protected from flowing air, is situated in middle floors, and built with thick and non-permeable materials and with small windows. These solutions were effective in order to fulfil sensory requirements.

Considering functional requirements, flexibility can be regarded as the major characteristic of the traditional Turkish house in various ways. The concept of the extended family was an important factor in shaping the traditional Turkish house; fathers, mothers, children, sons and daughters-in-law lived under the same roof [28]. The flexibility of the traditional Turkish room arises from the need to accommodate several nuclear families under the same roof. Therefore it becomes necessary to create a room layout that includes all private activities of a nuclear family. This understanding makes it possible to use less space for more activity and more people. Between these rooms there exists a semi-private hall called "sofa" used for getting together for all family members, sometimes neighbours and relatives. In this sense sofa was intended to be a place to socialise during different times of the day. Likely the courtyard was used to come together or perform some activities such as cooking, eating, washing especially for women. It was surrounded by stone walls in order to create the necessary privacy. So, both sofa and courtyard were places to fulfil social and psychological requirements. Spatial hierarchy, which arises from the organization of space, is another key characteristics of Turkish house. This hierarchy helps to acquire both privacy and sociability.

In the typical room of the Turkish House necessary storage units and other functional equipment including the fireplace/oven were integrated with the spatial envelope. The center of the room was free from fixed furniture creating the possibility to be used for many different activities with movable interior elements. According to Arat [29] the integration of necessary storage units and functional equipment with the spatial envelope helps to increase effective use of space. Bertram [30] argues that the flexible character of Turkish room arises from the integration of space with the fixed functional equipment that surrounds it.

\subsection{The north Italian rural house}

The typical, north Italian Rural House is the so-called Cascina, is a complex featured by the perfect coexistence between men, animals and agricultural work. It can be isolated, surrounded by fields, or sided with other cascine. It is usually articulated around a central 
Table 1: The evaluation of well-being determinants in the traditional Turkish house.

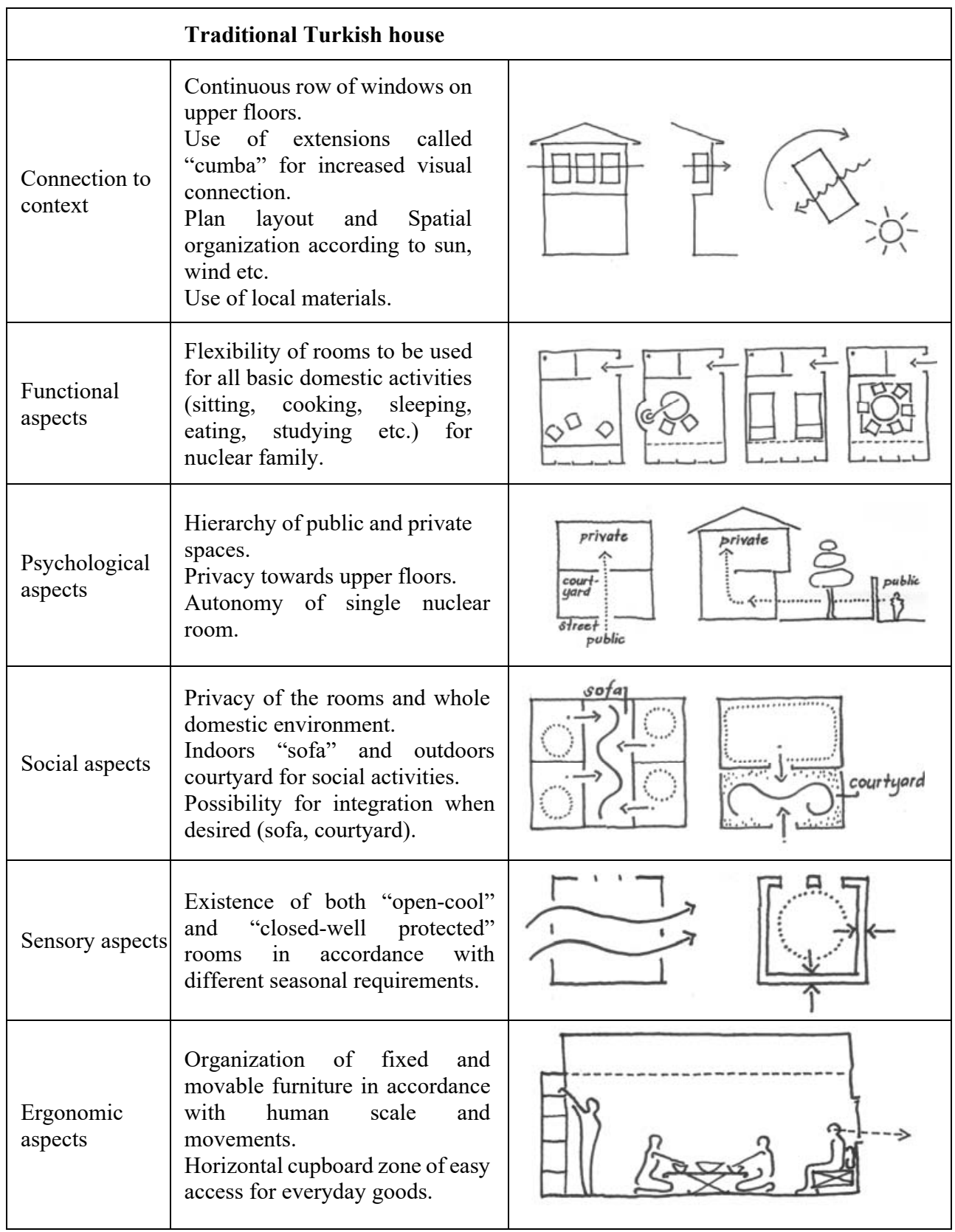

energy saving reasons, the outward-facing sides are almost completely free of openings, while the courtyard-facing sides are more open. One wing of the complex is used as a dwelling: on the ground floor there is a large kitchen with a fireplace, which can heat the upper floor where the bedrooms are, and furnishings are always very robust, simple and 
practical. Opposite is the wing dedicated to the stables (on the ground floor) and barns (which courtyard, which is the hub of all activities and the core of everyday life. For protection and are located on the upper floor, which is ventilated and insulated). Originally, upstairs there were bedrooms, which could take advantage of the livestock heating from downstairs.

This service wing is porched to create a ventilated area where it is possible to work even on rainy days that are very frequent in these regions. Thus the roofs are protruding and sloping, since water drainage is decisive. The walls are very thick to counter thermal raids between winter and summer. Construction materials are available on site (wood, clay, stone).

Since the central courtyard (which in Piemonte is called aia) plays a very important role, it must always be perfectly dry and sunny all year round. Often in the middle there is a well, or a water tank. In the aia small animals such as dogs and chickens roam freely.

The Cascina therefore hosts a small community that is quite self-sufficient, apparently introverted, where roles are clearly defined and where well-being is given by a balanced relationship with nature, work and environment.
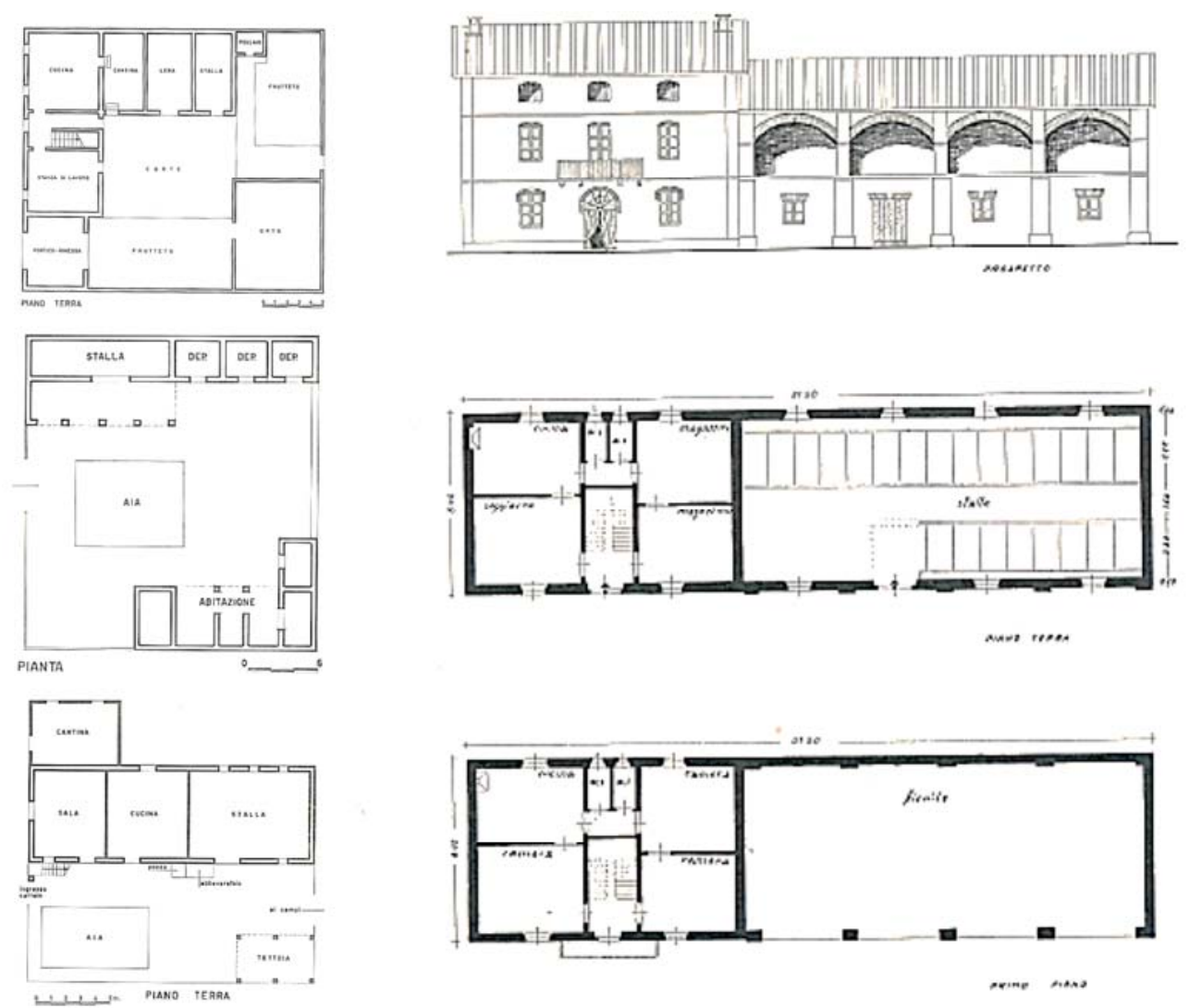

Figure 4: Variations in the typology of Cascina in northern Italy. Left: northern Piemonte, southern Piemonte, Lombardia [31]; Right: one-winged Cascina in Piemonte [32]. 
Table 2: The evaluation of well-being determinants in the north Italian rural house.

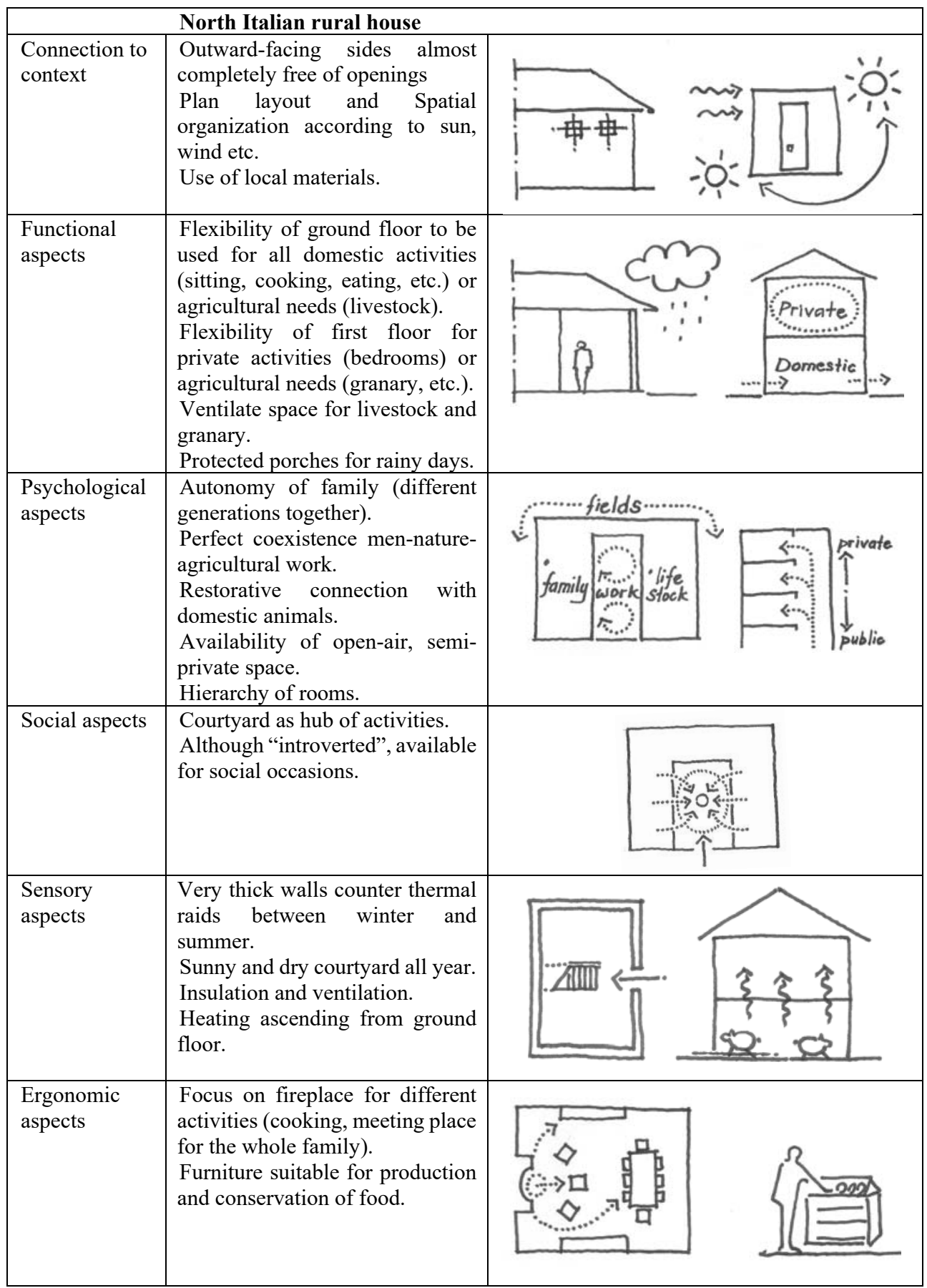




\section{CONCLUSION}

While studies on building shell and overall design have been considered as the most important aspects of sustainable architecture, the importance of sustainable interiors has been underestimated over the last decades. Examination of design principles in traditional home environments in Turkey and in Italy have shown that they mainly concentrate on the requirements of living from bigger scale to interior scale including all spaces and objects that surround us. This understanding creates a holistic approach that respond to the conditions of the environment in order to support human well-being as a natural outcome of sustainable solutions. On the other hand today's living environments attempt to fulfill well-being requirements by the use of artificial environment control systems that consume more energy and lack the authenticity of vernacular solutions. In this sense new design approaches need to consider both the potentials of contextual relations and human ways of living and requirements, which will lead to a significant contribution to human well-being in everyday living environments. The proposal of the well-being framework aims to structure the components of well-being according to contextual, functional, psychological, social, ergonomic and sensory aspects considering their inseparable relations that act together to construct human well-being.

[1] Naci, H. \& Ioannidis, J.P.A., Evaluation of wellness determinants and interventions by citizen scientists, JAMA, 314(2), p. 121, 2015. DOI: 10.1001/jama.2015.6160.

[2] Desmet, P.M.A. \& Pohlmeyer, A.E., Positive design: An introduction to design for subjective well-being. International Journal of Design, 7(3), pp. 5-19, 2013.

[3] Barcaccia, B., Esposito, G, Matarese, M., Bertolaso, M., Elvira, M. \& De Marinis, M.G., Defining quality of life: A wild-goose chase? Europe's Journal of Psychology, 9(1), pp. 185-203, 2013.

[4] Lyubomirsky, S., Sheldon, K.M. \& Schkade, D., Pursuing happiness: The architecture of sustainable change. Review of General Psychology, 9(2), pp. 111-131, 2005. DOI: 10.1037/1089-2680.9.2.111.

[5] Ryff, C.D. \& Singer, B., The contours of positive human health. Psychological Inquiry, 9(1), pp. 1-28, 1998. DOI: 10.1207/s15327965pli0901_1.

[6] Tov, W. \& Diener, E., Culture and subjective well-being. Handbook of cultural psychology, eds. S. Kitayama \& D. Cohen, pp. 691-713, Guilford: New York, 2007.

[7] Boyden, S., Biological Determinants of Optimal Health. Proceedings of Conference the Human Biology of Environmental Change in Blantyre Malawi, ed. D.J.M. Vorster, Apr. 5-12, International Biology Program: London, 1971.

[8] Petermans, A. \& Pohlmeyer, A.E., Design for subjective well-being in interior architecture. Proceedings of the 6th Annual Architectural Research Symposium, Finland, pp. 206-218, 2014.

[9] Brey, P., Design for the value of human well-being. Handbook of Ethics, Values, and Technological Design. Sources, Theory, Values and Application Domains, eds. J. Van Den Hoven, P. Vermaas \& I. Van De Poel, Springer, pp. 365-382, 2015.

[10] Online sources: How Wellness and Well-Being Went Mainstream. Online. www.ambius.com/blog/how-wellness-and-well-being-went-mainstream. Accessed on: Aug. 2017.

[11] Kellert, R., Building for Life: Designing and Understanding the Human-Nature Connection. Island Press: Washington D.C, 2005.

[12] Saglar Onay, N., Garip, B., Garip, E. A flexible user centered design model for social housing units. Tafter Journal, 97, 2017. 
[13] Salvendy G., Handbook of Human Factors and Ergonomics. John Wiley \& Sons: New Jersey, 2012.

[14] Phesant, S., Bodyspace: Anthropometry, Ergonomics and the Design of Work, Taylor \& Francis: London, 2003.

[15] Ryan, R.M. \& Deci, E.L., Self-determination theory and the facilitation of intrinsic motivation, social development, and well-being. American Psychologist, 55(1), pp. 68-78, 2000. DOI: 10.1037//0003-066x.55.1.68.

[16] Deci, E.L. \& Ryan, R.M., Intrinsic Motivation and Self-Determination in Human Behavior, Plenum: New York, 1985.

[17] Kupfer J., Privacy, autonomy, and self-concept. American Philosophical Quarterly, 24(1), pp. 81-89, 1987.

[18] Namazian, A. \& Mehdipour, A., Psychological demands of the built environment, privacy, personal space and territory in architecture. International Journal of Psychology and Behavioral Sciences, 3(4), pp. 109-113, 2013.

[19] Keyes, C.L.M., Social well-being. Social Psychology Quarterly, 61(2), pp. 121-140, 1998.

[20] Keyes, C.L.M. \& Shapiro, A.D., Social well-being in the United States: A descriptive epidemiology. How Healthy Are We? A National Study of Well-Being at Midlife, eds O.G. Brim, C. Ryff \& R. Kessler, University Chicago Press, 2004.

[21] Pallasma, J., The Eyes of the Skin, John Wiley \& Sons: Chichester, 2005.

[22] Zumthor, P., Atmospheres, Birkhauser: Basel, 2006.

[23] Unwin, S., Analyzing Architecture, Routledge: New York, 2009.

[24] Saglar Onay N., Analysing Spatial Potentials of Historic Buildings, Rimini: Maggioli Editore: Santarcangelo di Romagna, 2017.

[25] Ozorhon G. \& Ozorhon I.F., Learning from Mardin and Cumalıkızık: Turkish vernacular architecture in the context of sustainability, 3, pp. 175-189, 2014.

[26] Bozdogan, S., Vernacular architecture and identity politics: The case of Turkish house, TDSR, Vol. 7, No. II, 1996.

[27] Küçükerman, Ö., Kendi Mekanının Arayışı İçinde Türk Evi (Turkish House in Search of Spatial Identitiy). Türkiye Turing ve Otomobil Kurumu, 1989.

[28] Turgut, H. \& Unugur, M., Household patterns and the use of home: A case study of the traditional Turkish houses. Culture and Space in the Home Environments Research Series, 7, 1997.

[29] Arat, Y., Analysis of traditional Turkish house indoor components based on antropometric data; Konya houses. PhD thesis. Seljuk University Institute of Science and Technology, 2011.

[30] Bertram, C., Imagining the Turkish House, University of Texas Press: Austin, 2008.

[31] La Regina, F., Architettura rurale: problemi di storia e conservazione della civiltà edilizia contadina in Italia, Bologna Calderini, 1980.

[32] Medici, R., Architettura rurale: Esperienze della Bonifica, Bologna Edizioni agricole, 1956. 